(c) American Dairy Science Association, 2004.

\title{
Evaluation and Use of Three Cowside Tests for Detection of Subclinical Ketosis in Early Postpartum Cows
}

\author{
J. Carrier, S. Stewart, S. Godden, J. Fetrow, and P. Rapnicki \\ Veterinary Population Medicine Department, College of Veterinary Medicine, \\ University of Minnesota, St. Paul 55108
}

\begin{abstract}
The objective was to evaluate the performance of 3 cowside diagnostic tests for detection of subclinical ketosis, defined as a serum $\beta$-hydroxybutyrate (BHBA) concentration $\geq 1400 \mu \mathrm{mol} / \mathrm{L}$. On $16 \mathrm{~d}$ over a 5 -mo period, samples of serum, milk, and urine were collected on a large dairy facility from cows of all parities between 2 and 15 DIM. The sample proportion of subclinical ketosis was 7.6\% ( $\mathrm{n}=859$ samples from 545 cows). The KetoCheck powder (Great States Animal Health, St. Joseph, MO) detecting acetoacetate in milk samples was very specific (99\%) but poorly sensitive (41\%). Respective sensitivities and specificities of the Ketostix strip detecting acetoacetate in urine samples (Bayer Corporation, Elkhart, IN) were 78 and 96\% with a cut-off point of "small", or 49 and $99 \%$ with a cut-off of "moderate." The KetoTest strip (Sanwa Kagaku Kenkyusho Co. Ltd., Nagoya, Japan) using milk samples had a sensitivity and specificity of 73 and $96 \%$ with a cut-off of $100 \mu \mathrm{mol}$ of BHBA/L or 27 and $99 \%$ with a cut-off of $200 \mu \mathrm{mol}$ of BHBA/L. On average, use of the Ketostix at the "small" cut-off point or the KetoTest at $100 \mu \mathrm{mol} / \mathrm{L}$ would result in no more than 3 or 4 false positives per 100 cows screened, with prevalence levels ranging from 5 to $30 \%$, whereas the number of false negatives would range from one false negative at $5 \%$ prevalence to 7 or 8 false negatives at $30 \%$ prevalence. Either the Ketostix or KetoTest strips would provide acceptable results for screening individual cows on commercial dairies to detect subclinical ketosis. Over this prevalence range, the KetoCheck powder test would have limited application as a screening test. Despite only one false positive per 100 animals screened, false negatives resulting from screening with the KetoCheck test would be too frequent, ranging from 3 false negatives at $5 \%$ prevalence to 18 at $30 \%$ prevalence in a population of 100 tested cows. Finally, given their relative imprecision, use of
\end{abstract}

Received March 9, 2004.

Accepted August 9, 2004

Corresponding author: J. Carrier; e-mail: carri018@umn.edu. any of these individual cowside tests to estimate herd prevalence must be done cautiously, especially when only a small number of animals are sampled.

(Key words: subclinical ketosis, diagnostic test, urine, milk)

Abbreviation key: AcAc = acetoacetate.

\section{INTRODUCTION}

Subclinical ketosis is defined as abnormal concentrations of circulating ketone bodies in the absence of clinical signs of ketosis (Andersson, 1988). Reported overall prevalence of subclinical ketosis ranges from $6.9 \%$ to $14.1 \%$ in the first 2 mo of lactation (Dohoo and Martin, 1984; Andersson and Emanuelson, 1985; Nielen et al., 1994; Duffield et al., 1997). However, prevalence as high as $34 \%$ has been reported (Kauppinen, 1983; Duffield et al., 1998). On an individual herd basis, Dohoo and Martin (1984) reported that herd prevalence in cows from 0 to 65 DIM varied from 0 to $33.9 \%$ in a study where the overall prevalence was $12.1 \%$. The peak prevalence of subclinical ketosis occurs in the first 2 wk of lactation (Duffield et al., 1997, 1998). Subclinical ketosis in dairy cattle can lead to economic losses through decreased milk production, decreased reproductive performance, increased risk of displaced abomasum, and increased risk of clinical ketosis. The effects of subclinical ketosis have been reviewed elsewhere (Andersson, 1988; Duffield, 2000).

It has been assumed that diagnosis of individual cases of subclinical ketosis at an earlier point in the course of the disease would permit earlier treatment and help mitigate further losses (Enjalbert et al., 2001; Geishauser et al., 2001). Also, tests results could be used on a herd basis to determine the level of subclinical ketosis and indicate the necessity for further investigations and management improvements.

The gold standard diagnostic test for subclinical ketosis is the measurement of BHBA in serum or plasma because of its stability (Duffield, 2000; Herdt, 2000). The conversion of BHBA measurement from the Système International unit ( $\mu \mathrm{mol} / \mathrm{L})$ to the US equivalent unit $(\mathrm{mg} / \mathrm{dL})$ is done by dividing the measurement 
in $\mu \mathrm{mol} / \mathrm{L}$ by 96.05 (American Medical Association, 2004). To distinguish between normal cows and cows with abnormal levels of BHBA, a threshold value of $1400 \mu \mathrm{mol} / \mathrm{L}(14.6 \mathrm{mg} / \mathrm{dL})$ is recommended, based on the increased risk of displaced abomasum or clinical ketosis above this level (Duffield, 1997).

Although serum BHBA measurement is useful for periodic herd assessment or for research purposes, it is neither convenient nor cost-effective for use as a routine cowside diagnostic test for early detection and treatment of the disease. Milk and urine also contain ketone bodies and can be used for a cowside diagnostic. Total ketone body concentrations are reported to be approximately 4 times higher in urine than blood (Schultz, 1971). The concentration of BHBA in milk is about one-eighth of the concentration in blood, whereas the concentration of acetoacetate (AcAc) in milk is 40 to $45 \%$ of that of blood (Andersson, 1984; Enjalbert et al., 2001). The correlation coefficients of blood BHBA with milk BHBA and milk AcAc were 0.66 and 0.62, respectively (Enjalbert et al., 2001). Commonly used cowside diagnostic tests for ketosis are typically based on the degree of color change occurring when sodium nitroprusside reacts with AcAc and to a lesser extent with acetone (Adler et al., 1956). These nitroprusside tests are available as powders (generally used on milk) and as urinalysis strips. Because the color change is more intense in the presence of higher levels of ketone bodies (Adler et al., 1956), the nitroprusside tests can be used semiquantitatively. Tests marketed as strips often have a reference color chart to aid in estimating the level of ketone bodies.

A dipstick test for detection of BHBA in milk has also been recently developed and evaluated (Geishauser et al., 1998, 2000; Jorritsma et al., 1998; Enjalbert et al., 2001; Osborne et al., 2002). This strip test turns purple based on its reaction with abnormal levels of BHBA in milk and can also be used semiquantitatively when paired with the accompanying color chart.

The reported sensitivity for commercial nitroprusside powders used on milk for detection of subclinical ketosis ranges from 28 to 43\% (Duffield, 1997; Geishauser et al., 1998). There is a report of a noncommercially-prepared nitroprusside powder with $90 \%$ sensitivity and $96 \%$ specificity, but such performances have not been repeated (Nielen et al., 1994). The specificity of nitroprusside powder tests on milk ranges between 96 and 100\% (Nielen et al., 1994; Duffield, 1997; Geishauser et al., 1998).

There are very few reports of the performance of cowside diagnostic tests to detect subclinical ketosis with urine samples. A nitroprusside tablet showed a sensitivity of $100 \%$ and a specificity of $59 \%$ compared with serum BHBA levels of $1400 \mu \mathrm{mol} / \mathrm{L}$ and higher
(Nielen et al., 1994). A sensitivity of $97 \%$ and a specificity of $60 \%$ were found for the test strip detecting BHBA (instead of AcAc) when used on urine in the first 2 wk after calving (Osborne et al., 2002). There is no report of test performance in cattle for commonly used nitroprusside urinalysis strips detecting AcAc.

In accordance with these previous results, conventional wisdom is that milk powder tests are not sensitive enough for detection of subclinical ketosis (report too many false negatives) and that urine tests are not specific enough (report too many false positives).

The strip detecting BHBA has been reported to be the most accurate ketosis cowside test available when used on milk (Geishauser et al., 1998, 2000; Duffield, 2000). Using $100 \mu \mathrm{mol}$ of BHBA/L of milk as a cut-off, this test showed a sensitivity of $72 \%$ and a specificity of $89 \%$ when compared with serum BHBA levels greater than $1200 \mu \mathrm{mol} / \mathrm{L}$ (Geishauser et al., 1998). With the same BHBA thresholds to define a positive test and a ketotic cow, Enjalbert et al. (2001) obtained a sensitivity of $96 \%$ and a specificity of $63 \%$. Using $1400 \mu \mathrm{mol} / \mathrm{L}$ of serum BHBA for the definition of subclinical ketosis, various estimates of sensitivity and specificity, respectively, have been reported: 88 and $82 \%$ (Jorritsma et al., 1998); 80 and 76\% (Geishauser et al., 2000); and 95 and 69\% (Osborne et al., 2002).

The objective of this study was to determine the performance of 3 cowside diagnostic tests compared with serum BHBA and to evaluate their usefulness in a herd-screening process. The tests were: 1) a commonly used nitroprusside powder test detecting milk AcAc (KetoCheck, Great States Animal Health, St. Joseph, MO), 2) a commonly used nitroprusside urine strip detecting AcAc (Ketostix, Bayer Corporation, Elkhart, IN), and 3) a milk BHBA test strip (KetoTest, Sanwa Kagaku Kenkyusho Co. Ltd., Nagoya, Japan, distributed by Elanco Animal Health/Provel, a division of Eli Lilly Canada Inc., Guelph, Canada).

\section{MATERIALS AND METHODS}

\section{Sampling and Testing}

The study was performed in a transition cow management facility housing dry and just-fresh cows for 2 large commercial dairies (total 2500 milking cows) in western Wisconsin. The dairies of origin were producing 34 and $38 \mathrm{~kg}$ of milk/d, respectively, during the study period. The transition facility is a 4-row, tail-to-tail, sand-bedded, drive-through free-stall barn housing 400 cows and heifers in late pregnancy or at the beginning of their lactation. The facility can be divided into 13 separate free-stall pens, and rations are prepared for 4 different management groups: faroff dry cows, transition dry cows, transition prefresh 
heifers, and fresh cows (including primiparous). Fresh cows were milked 3 times/d until January 14, 2003, and then 4 times/d thereafter.

Early postpartum cows were sampled on 16 different days from September 12, 2002, to January 17, 2003, and included all recently calved cows except for cows calving on the day of sampling or the day before. Therefore, cows were mostly between 2 and $15 \mathrm{~d}$ postpartum.

The composite milk samples were collected in the parlor from the milk meter (Provantage meter, BouMatic, Madison, WI) using a sampler attachment approved for use in DHIA. The free-catch samples of urine were collected in the headlocks during the regular screening process immediately after the same milking and were obtained either from spontaneous or stimulated micturition. The blood samples were drawn from the coccygeal vessels at the same time using vacuum tubes with clot activator and gel for serum separation (Becton Dickinson and Company, Franklin Lakes, NJ). Tubes were kept at room temperature and were centrifuged for $15 \mathrm{~min}$ at $1380 \times \mathrm{g}$ within $4 \mathrm{~h}$ of collection.

Serum was frozen until delivery to the laboratory for further analysis. To analyze serum samples for BHBA, the enzymatic tests used were the Sigma $\beta$ hydroxybutyrate kit (Sigma-Aldrich Corp., St. Louis, MO) on the BM/Hitachi 911 automated analyzer (Roche Diagnostics/Boehringer Mannheim Corporation, Indianapolis, IN), or the Ranbut D-3-hydroxybutyrate kit (Randox Laboratories Ltd., San Diego, CA) on the Synchron CX-5 analyzer (Beckman Coulter, Inc., Fullerton, CA). Serum samples were analyzed alongside control sera of low concentration of BHBA (580, 650 , or $960 \mu \mathrm{mol} / \mathrm{L}$ ) and high concentration of BHBA $(6100,6400$, or $7200 \mu \mathrm{mol} / \mathrm{L})$.

The Ketostix urine strip test was directly wetted from the urine stream. The result was read after 5 to $10 \mathrm{~s}$ of contact and was recorded immediately according to the color scale provided with the test. The scale is made of 6 different color blocks that represent nominal concentrations of acetoacetate; actual values vary around the nominal values. The categories are negative, trace $(490 \mu \mathrm{mol}$ of AcAc/L, shown as $5 \mathrm{mg} /$ $\mathrm{dL}$ on the scale), small $(1470 \mu \mathrm{mol} / \mathrm{L}$ or $15 \mathrm{mg} / \mathrm{dL})$, moderate $(3920 \mu \mathrm{mol} / \mathrm{L}$ or $40 \mathrm{mg} / \mathrm{dL})$, large $(7840 \mu \mathrm{mol} / \mathrm{L}$ or $80 \mathrm{mg} / \mathrm{dL})$ and a second large $(15,700 \mu \mathrm{mol} / \mathrm{L}$ or 160 $\mathrm{mg} / \mathrm{dL}$ ). The second large category will be referred to as "very large" throughout the article. The KetoCheck powder test on milk was performed in the farm laboratory area after completion of the milking and the result was recorded as negative, trace, moderate, or large after 2 min of contact based on the degree of purple discoloration (none, light, intermediate, and dark). Be- cause no color scale was available with the KetoCheck powder, classification of results was more subjective than with the other tests used. However, differentiation between no discoloration and some discoloration ( $\geq$ trace) does not require a color scale. The KetoTest milk strip test measuring BHBA was also performed in the farm laboratory area after milking and the result was read after $1 \mathrm{~min}$ and recorded according to the color scale provided with the test. Similarly to the Ketostix, the color scale for the KetoTest shows 6 different color blocks that correspond to nominal levels of $0,50,100,200,500$, and $1000 \mu \mathrm{mol}$ of BHBA/L of milk respectively. Urine tests were performed by the 2 herdsmen and the principal author. All milk tests were done by the principal author or a research technician, except on the first day of sampling, when another author did them.

A total of 859 serum samples were collected from 545 cows (168 primiparous and 377 multiparous). Some cowside tests results were missing. Only 710 urine samples were obtained out of 859 possibilities (83\%). The distribution of serum BHBA was similar in cows with and without a urine sample. Nine observations out of 859 did not have a milk sample. Of the 850 observations with a milk sample, 5 did not have the nitroprusside powder test evaluated, but did have the milk BHBA strip result available.

\section{Tests Characteristics}

The cowside tests characteristics were calculated over the range of possible cut-off points for each test, using the serum BHBA value as the gold standard for the determination of subclinical ketosis. Sensitivity was calculated as the proportion of the cows with serum BHBA greater than or equal to $1400 \mu \mathrm{mol} / \mathrm{L}$ correctly identified as positive by the test. Specificity was calculated as the proportion of cows with a BHBA level less than $1400 \mu \mathrm{mol} / \mathrm{L}$ correctly identified as negative by the test. Standard errors for sensitivity and specificity were calculated using normal approximation of standard errors for proportions (Dawson and Trapp, 2001). Finally, likelihood ratios were calculated. The likelihood ratio of a positive test is the ratio of the posttest odds of disease divided by the pretest odds (Dohoo et al., 2003). It is calculated by dividing the sensitivity of the test by the false positive rate (1 specificity). Two approaches can be used to calculate the likelihood ratios (Dohoo et al., 2003). The first is the cut-off specific approach. As with the sensitivity and specificity calculations, all animals with a cowside test result equal to the chosen cut-off point or above are considered test-positive. The second approach is the category-specific likelihood ratio, which takes ad- 
vantages of the ordinal or the continuous nature of the test results. The calculations are similar to the first approach, except that only the animals found with the test result of interest are considered test-positive, with animals found in categories both below and above it considered test-negative. This second approach allows predicting the odds of disease for a specific cowside test result. To allow comparisons with other reports found in the literature, both methods were used to estimate likelihood ratios.

\section{Calculations for Comparison of the Tests in Screening Situations}

Sensitivity and specificity represent the probability of a certain test result (positive or negative), given the known disease status of an individual. However, knowing the sensitivity and specificity does not directly show how well a test may perform when applied to animals of unknown disease status; the actual number of true and false diagnostics will also depend on the prevalence of the disease (Dohoo et al., 2003). For example, in the screening of 100 animals with a disease prevalence of $5 \%$, a test with a sensitivity of $60 \%$ and a specificity of $80 \%$ would result in 2 false negatives and 19 false positives, whereas, with a disease prevalence of $30 \%$, the same test would result in 12 false negatives and 14 false positives. This effect of the disease prevalence on the number of diagnostic errors thus complicates the comparison of diagnostic tests that have various combinations of sensitivity and specificity, as some tests may be more suitable in some situations, and less in others (Martin, 1988). Consequently, to evaluate and compare the 3 cowside tests in different screening situations, the number of true and false diagnostics was calculated over 3 likely hypothetical levels of prevalence of subclinical ketosis. The 3 levels of prevalence selected represented a low prevalence $(5 \%)$, a moderate prevalence $(15 \%)$, and a high prevalence $(30 \%)$.

The hypothetical prevalence levels were first used to calculate the number of normal and ketotic animals in each situation. Then, for each cowside test at each cut-off point, the expected numbers of true positive, true negative, false positive, and false negative diagnostics were calculated. Finally, the predictive values of the tests were calculated. The positive predictive value is the proportion of the animals with positive tests that are truly diseased, and the negative predictive value is the proportion of the animals with negative tests that are truly nondiseased.

\section{Calculations for Interpretation of Test Results at the Herd Level}

Herd screening for subclinical ketosis can be used for purposes beyond the detection and treatment of the disease in individual animals. Estimates of the disease prevalence in a group could be obtained from the cowside diagnostic tests results and could be used to identify subclinical ketosis problems at the herd level.

The apparent prevalence (i.e., the prevalence of positive tests results) is frequently not a good estimate of the true prevalence because of the false negative and false positive diagnostics and may overestimate or underestimate the true prevalence (Martin, 1984). However, when the sensitivity (Se) and the specificity (Sp) of a test are known, the true prevalence can be estimated by the following function (Dohoo et al., 2003):

$$
\text { True prevalence }=\frac{\text { Apparent Prevalence }+\mathrm{Sp}-1}{\mathrm{Se}+\mathrm{Sp}-1}
$$

To evaluate the precision of the cowside tests for predicting the true disease prevalence, on each sampling day and for every diagnostic tests and cut-off points, the observed true prevalence, the apparent prevalence, and the predicted true prevalence, as estimated from the apparent prevalence and the overall sensitivity and specificity of the tests, were calculated.

\section{RESULTS AND DISCUSSION}

\section{Sample Description}

The overall proportion of serum BHBA levels of 1400 $\mu \mathrm{mol} / \mathrm{L}$ and higher was $7.6 \%$, ranging by sampling day from 0 to $20.8 \%$. The distribution of BHBA concentrations is shown in Figure 1. The proportion of positive serum samples per week of lactation and parity is shown in Table 1.

\section{Tests Characteristics}

Sensitivity and specificity of all 3 cowside tests are reported in Table 2, with standard errors. Likelihood ratios are shown in Table 3. The KetoCheck powder was highly specific (99\%) but poorly sensitive (41\%), even at the most sensitive cut-off point. These findings support earlier reports on the nitroprusside powder tests on milk (Duffield, 1997; Geishauser et al., 1998).

The Ketostix test used with the cut-off point of "small", as specified on the container, had a sensitivity of $78 \%$ and a specificity of $96 \%$. These results indicate that the Ketostix test is a reliable cowside test to diag- 


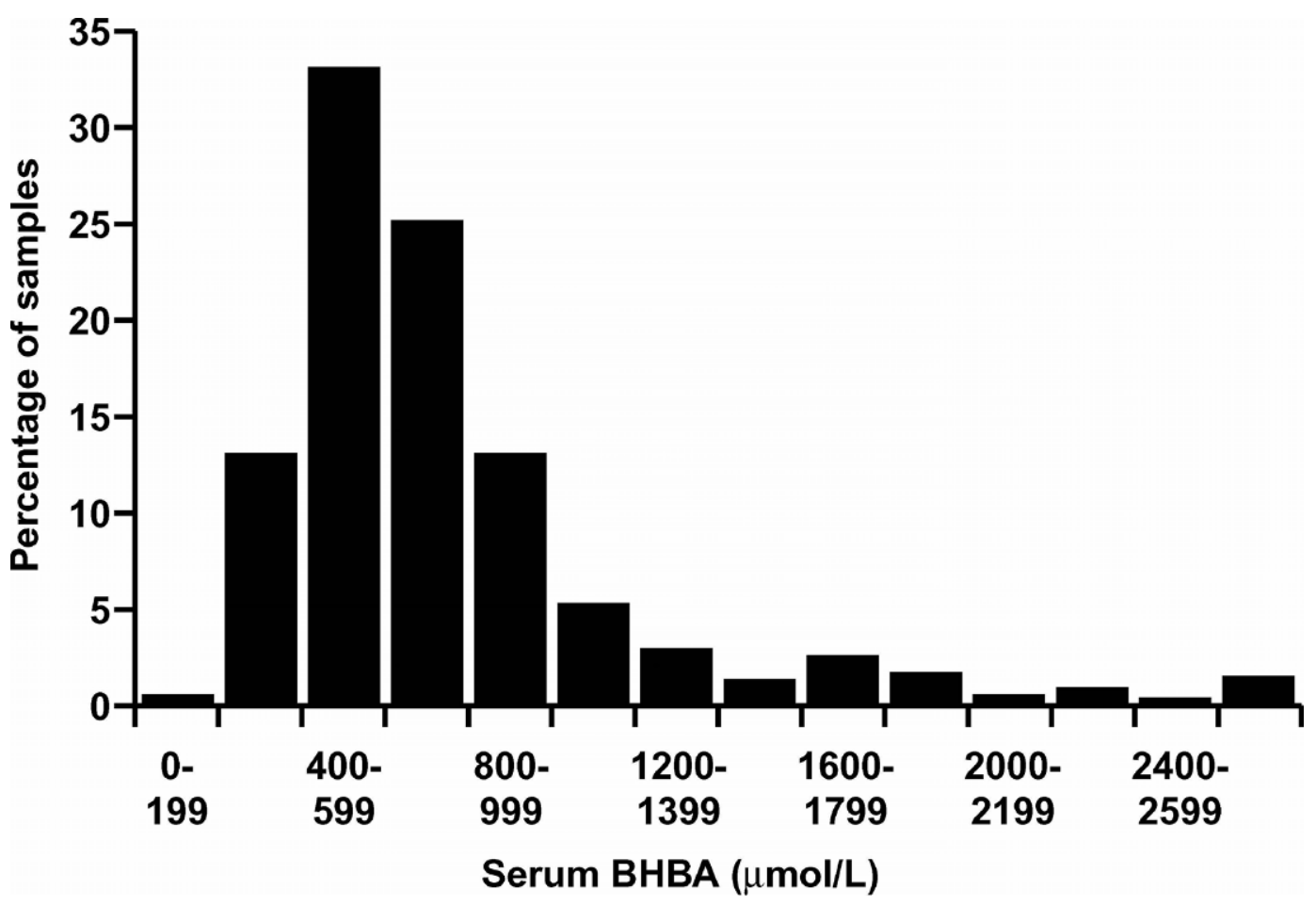

Figure 1. Relative frequency distribution of serum $\beta$-hydroxybutyrate (BHBA) concentrations in 859 serum samples from 545 cows. The last category includes all BHBA measurements $\geq 2600 \mu \mathrm{mol} / \mathrm{L}$.

nose subclinical ketosis. However, these nitroprusside strips must be read promptly after contact with urine, as the color tends to darken with time. These results differ from the earlier reports on the lack of specificity of the nitroprusside tablet or the BHBA strip used on urine (Nielen et al., 1994; Osborne et al., 2002).

Using a cut-off milk BHBA concentration of 100 $\mu \mathrm{mol} / \mathrm{L}$, the KetoTest strip had a sensitivity of $73 \%$ and a specificity of $96 \%$. These results differ from previous reports using the same definition of subclinical ketosis (Jorritsma et al., 1998; Geishauser et al., 2000; Osborne et al., 2002). The KetoTest in this study resulted in a lower sensitivity ( 73 vs. 88,80 , and $95 \%$, respectively in the cited studies), but a much improved specificity $(96 \%$ in this study vs. 82,76 , and $69 \%$ respectively). Although some of the difference in sensitivity

Table 1. Proportion of serum samples with BHBA $\geq 1400 \mu \mathrm{mol} / \mathrm{L}$ in primiparous and multiparous cows by week of lactation.

\begin{tabular}{llll}
\hline & \multicolumn{3}{c}{ Number of positive samples/total (\%) } \\
\cline { 2 - 4 } Parity & Week 1 & Week 2 & $\geq$ Week 3 \\
\hline Primiparous & $8 / 120$ & $6 / 128$ & $0 / 21$ \\
& $(6.7)$ & $(4.7)$ & $(0.0)$ \\
Multiparous & $25 / 301$ & $24 / 258$ & $2 / 31$ \\
& $(8.3)$ & $(9.3)$ & $(6.5)$ \\
\hline
\end{tabular}

may only be due to sampling variation (in light of the small number of ketotic animals included in the denominator), it is very unlikely that the observed difference in specificity was only due to the sampling variation. Reasons for these differences are unclear, but there may have been variation in the reading of the test strips among studies. Such discrepancies between reports also show that ketosis cowside tests may be prone to subjective interpretation and therefore may be difficult to standardize.

\section{Comparison of the Tests in Screening Situations}

The choice of a cut-off point for a diagnostic test depends of the consequence of having a false-positive or a false-negative result, multiplied by the number of each diagnostic error in a given situation. Lowering the cut-off point to increase sensitivity and decrease the number of false negatives will decrease the specificity and raise the number of false positives. Raising the cut-off point will have the opposite effects (Martin, 1984). The cost of a false-positive ketosis test result followed by unnecessary treatment may be relatively low with limited risk to the animal, but could become costly and time-consuming if there were a large number of unnecessary treatments. On the other hand, the 
Table 2. Performance of 3 cowside diagnostic tests ${ }^{1}$ for detection of subclinical ketosis in fresh cows defined as concentration of serum BHBA $\geq 1400 \mu \mathrm{mol} / \mathrm{L}$.

\begin{tabular}{|c|c|c|c|c|c|c|}
\hline \multirow[b]{2}{*}{ Test and threshold } & \multirow[b]{2}{*}{$\mathrm{n}^{2}$} & \multirow[b]{2}{*}{ n ket $^{3}$} & \multicolumn{2}{|c|}{ Sensitivity (\%) } & \multicolumn{2}{|c|}{ Specificity (\%) } \\
\hline & & & Estimate & (SE) & Estimate & $(\mathrm{SE})$ \\
\hline KetoCheck powder for milk AcAc & 845 & 63 & & & & \\
\hline$\geq$ trace & & & 41 & $(6.2)$ & 99 & $(0.4)$ \\
\hline$\geq$ moderate & & & 10 & (3.7) & 100 & $(0.0)$ \\
\hline$\geq$ large & & & 2 & (1.6) & 100 & $(0.0)$ \\
\hline Ketostix strip for urine AcAc & 710 & 49 & & & & \\
\hline$\geq$ trace & & & 90 & $(4.3)$ & 86 & (1.4) \\
\hline$\geq$ small & & & 78 & $(6.0)$ & 96 & $(0.8)$ \\
\hline$\geq$ moderate & & & 49 & (7.1) & 99 & $(0.4)$ \\
\hline$\geq$ large & & & 12 & $(4.7)$ & 100 & $(0.0)$ \\
\hline zvery large & & & 4 & $(2.8)$ & 100 & $(0.0)$ \\
\hline KetoTest strip for milk BHBA $(\mu \mathrm{mol} / \mathrm{L})$ & 850 & 64 & & & & \\
\hline$\geq 50$ & & & 88 & $(4.1)$ & 90 & $(1.1)$ \\
\hline$\geq 100$ & & & 73 & $(5.5)$ & 96 & $(0.7)$ \\
\hline$\geq 200$ & & & 27 & $(5.5)$ & 99 & $(0.3)$ \\
\hline$\geq 500$ & & & 3 & $(2.2)$ & 100 & $(0.0)$ \\
\hline$\geq 1000$ & & & 2 & (1.6) & 100 & $(0.0)$ \\
\hline
\end{tabular}

\footnotetext{
${ }^{1}$ KetoCheck, Great States Animal Health, St. Joseph, MO: Levels correspond to the degree of purple discoloration (none, light, intermediate and dark); Ketostix, Bayer Corporation, Elkhart, IN: Trace = 490; small $=1470 ;$ moderate $=3920 ;$ large $=7840$ and very large $=15,700 \mu \mathrm{mol} / \mathrm{L}$ of acetoacetate $($ AcAc $) ;$ KetoTest , Sanwa Kagaku Kenkyusho Co. Ltd., Nagoya, Japan.

${ }^{2}$ Number of observations paired with a serum BHBA measurement for each cowside test.

${ }^{3}$ Number of observations with serum BHBA level $\geq 1400 \mu \mathrm{mol} / \mathrm{L}$.
}

costs of false-negative ketosis tests are more difficult to quantify. Although it has been estimated that subclinical ketosis caused a monetary loss of $\$ 78 /$ case (Geishauser et al., 2001), it is not yet clear how much early treatment of subclinical ketosis cases will limit losses (Geishauser et al., 2001). It is also unclear what level of ketonemia warrants treatment. However, it is likely that the cost of one missed case of subclinical ketosis represents a greater loss compared with one treatment unnecessarily administered. This effect might be mitigated, however, if cows are routinely screened on successive days in the early postpartum period. Missing a positive diagnosis on one day might be corrected when the cow is tested the next day.

Table 4 shows the estimated number of true and false diagnostics resulting from the hypothetical use of all 3 cowside tests in the screening process of 100 fresh cows with a disease prevalence of 5,15 , and $30 \%$, along with the associated predictive values. The poor sensitivity of the KetoCheck powder used on milk limits its potential use as a cowside-screening tool for subclinical ketosis because almost $60 \%$ of the truly affected cows would go undetected, even at the most sensitive cut-off point. As prevalence rises, so does the number of false negatives per 100 animals. On the other hand, if a cow has a positive test result with this powder, there is an excellent chance the cow truly is positive $(+\mathrm{PV}=68 \%$ at $5 \%$ prevalence, $88 \%$ at $15 \%$ prevalence, and $95 \%$ at $30 \%$ prevalence). The number of false positive animals identified with the KetoCheck powder would be no greater than one cow per 100 animals screened in the range of prevalence shown here.

The same problem of excessively low sensitivity is seen with the Ketostix urinalysis strip used at cut-off points of moderate, large, and very large, and with the KetoTest strip at the cut-off points of $200 \mu \mathrm{mol}$ of $\mathrm{BHBA} / \mathrm{L}$ of milk or higher. Used at these cut-off points, the tests would miss 51 to $98 \%$ of the cases. However, almost no animal with a positive test at these thresholds would be a false positive. Neither the Ketostix urine strip nor the KetoTest milk strip should be used at their most sensitive cut-off point due to the potentially excessive number of false-positive diagnostics.

The Ketostix urine strip (using the "small" cut-off point) and the KetoTest milk strip (using the $100 \mu \mathrm{mol} /$ L cut-off point) had sensitivities greater than $73 \%$, meaning that they would detect at least 3 out of 4 true cases of subclinical ketosis. Also, with these 2 tests, 3 to 4 animals per 100 animals would be false positives with a prevalence ranging between 5 and $30 \%$. This number of false positives should not represent an excessive cost relative to the gain resulting from the major decrease in the number of false negatives in comparison to the next higher cut-off ("moderate" urinary ketones, and $200 \mu \mathrm{mol}$ of BHBA/L of milk) when prevalence is higher (15 and 30\%). Careful evaluation of the cost-benefit is warranted in low prevalence scenarios $(<5 \%)$, as indicated by the higher number of false positives compared with the number of false neg- 
Table 3. Likelihood ratio of a positive test for different levels of KetoCheck, Ketostix, and KetoTest.

\begin{tabular}{lll}
\hline & \multicolumn{2}{c}{ Likelihood ratio } \\
\cline { 2 - 3 } Test and level & Cut-off specific ${ }^{1}$ & Category-specific $^{2}$ \\
\hline KetoCheck & \\
negative & powder for milk acetoacetate & 0.6 \\
trace & - & 31 \\
moderate & 40 & $\infty$ \\
large & $\infty^{4}$ & $\infty$ \\
Ketostix & strip for urine acetoacetate & 0.1 \\
negative & - & 1.2 \\
trace & 6.4 & 9.4 \\
small & 20 & 40 \\
moderate & 54 & $\infty$ \\
large & $\infty$ & $\infty$ \\
very large & $\infty$ & \\
KetoTest strip for milk & BHBA ( $\mu$ mol/L) & 0.1 \\
0 & - & 2.6 \\
50 & 8.8 & 12 \\
100 & 16 & 37 \\
200 & 42 & $\infty$ \\
500 & $\infty$ & $\infty$ \\
1000 & $\infty$ & \\
\hline
\end{tabular}

${ }^{1}$ Cut-off specific likelihood ratio: likelihood ratio of a positive test for tests results at the level or above. The interpretation is that the odds of subclinical ketosis at this cut-off point or above are "n" times the odds of subclinical ketosis in the source population.

${ }^{2}$ Category-specific likelihood ratio: likelihood ratio for a test result at the specific level only. The interpretation is that the odds of subclinical ketosis at this level are "n" times the odds of subclinical ketosis in the source population.

${ }^{3}$ KetoCheck levels correspond to the degree of purple discoloration (none, light, intermediate and dark).

${ }^{4}$ The likelihood ratio is infinity when there are no false positive diagnoses.

${ }^{5}$ Trace $=490 ;$ small $=1470 ;$ moderate $=3920 ;$ large $=7840$ and very large $=15,700 \mu \mathrm{mol} / \mathrm{L}$ of acetoacetate.

atives at the lower cut-off points ("small" urinary ketones or $100 \mu \mathrm{mol} / \mathrm{L}$ of BHBA of milk) and also by the similar total number of errors that would result if the next higher cut-off point was used.

The sensitivity and specificity of a monitoring program with repeated measurements of the same animals over time cannot be directly extrapolated from the sensitivity and the specificity of an individual diagnostic test (Martin, 1984). Along with the test characteristics, the sampling frame (i.e., the number of screening tests and the interval between the tests) can also have an important effect on the net sensitivity and the net specificity of the screening program to detect incident cases of subclinical ketosis. For example, if 100 ketosis-free animals are screened using a test with $95 \%$ specificity, 5 would be false positives. If the cowside tests results are perfectly correlated within subject over time, the same 5 animals would be expected to be false positive again every time the testing is done, resulting in a stable net specificity of the program at $95 \%$. However, it is more likely that the cowside tests results are not perfectly correlated within cows over time and that every time the test is performed, some new false positives would be found, resulting in a decrease in net specificity of the screening program compared with the test specificity itself.

Likewise, the repeated measurement of milk or urine ketone bodies over time is likely to increase the sensitivity of the monitoring program to detect an abnormal cow, especially considering that ketosis level may increase if a cow is left untreated and that the sensitivity of the cowside tests increases with ketone body concentration. Therefore, because repeated measurements are likely to decrease specificity and increase sensitivity of the screening program compared with the test itself, selection of a cut-off point with a higher specificity (and consequently a lower sensitivity) may be warranted, depending on the sampling frame chosen. Moreover, the ketone body levels within individual cows may also vary over time and result in placing cows in different subclinical ketosis classifications using these individual diagnostic tests. Therefore, attempts to estimate incident cases over time cannot be directly extrapolated from the sensitivity and the specificity of an individual diagnostic test. The correlation between repeated measurements of ketone bodies in urine or milk, as well as the dynamics of the disease, could not be evaluated in this study and need further investigation.

Selection of a test for use as a regular herd-screening tool for individual cases of subclinical ketosis would also involve weighing the differences between the tests regarding the price of the tests themselves, the labor costs, the ease of sampling (milk vs. urine), and the facilities available to restrain animals for sample collection.

\section{Interpretation of Test Results at the Herd Level}

The 16 groups of fresh cows sampled comprised between 31 and 70 individuals (mean of 53 cows per group for both milk tests and 44 cows per group for the urine test). Figure 2 shows the true subclinical ketosis prevalence compared with the apparent test prevalence for all 3 cowside tests at various cut-off points. The points represent the 16 sampling days, and the line is the predicted prevalence calculated as the function of the apparent test prevalence, the overall sensitivity and the overall specificity of the tests; the line is not the fitted regression of true prevalence over test prevalence, as the mathematical relation between true and apparent prevalence is already known (Dohoo et al., 2003).

The precision of the cowside tests to predict the true prevalence in groups of moderate size appears limited 
Table 4. Estimated number of true positive (TP), true negative (TN), false positive (FP), and false negative (FN) diagnoses, with the calculated predictive values (PV), expected in the screening of 100 fresh cows for the detection of subclinical ketosis using 3 cowside tests ${ }^{1}$ independently, with prevalence levels of 5 , 15 , and $30 \%$. Calculations were done before sensitivity and specificity values were rounded.

\begin{tabular}{|c|c|c|c|c|c|c|c|c|c|c|c|c|c|c|c|c|c|c|c|c|}
\hline \multirow[b]{2}{*}{ Test and threshold } & \multicolumn{2}{|c|}{$\begin{array}{c}\text { Disease prevalence } \\
\text { Number of cases } \\
\text { Number of normal cows }\end{array}$} & \multicolumn{6}{|c|}{$\begin{array}{c}5 \% \\
5 \text { cows } \\
95 \text { cows }\end{array}$} & \multicolumn{6}{|c|}{$\begin{array}{c}15 \% \\
15 \text { cows } \\
85 \text { cows }\end{array}$} & \multicolumn{6}{|c|}{$\begin{array}{l}30 \% \\
30 \text { cows } \\
70 \text { cows }\end{array}$} \\
\hline & $\begin{array}{l}\mathrm{Se}^{2} \\
(\%)\end{array}$ & $\begin{array}{l}\mathrm{Sp}^{3} \\
(\%)\end{array}$ & $\mathrm{TP}$ & $\mathrm{TN}$ & FP & $\mathrm{FN}$ & $\begin{array}{l}+\mathrm{PV}^{4} \\
(\%)\end{array}$ & $\begin{array}{l}-\mathrm{PV}^{5} \\
(\%)\end{array}$ & $\mathrm{TP}$ & $\mathrm{TN}$ & FP & $\mathrm{FN}$ & $\begin{array}{l}+\mathrm{PV} \\
(\%)\end{array}$ & $\begin{array}{l}-\mathrm{PV} \\
(\%)\end{array}$ & $\mathrm{TP}$ & $\mathrm{TN}$ & FP & $\mathrm{FN}$ & $\begin{array}{l}+\mathrm{PV} \\
(\%)\end{array}$ & $\begin{array}{l}-\mathrm{PV} \\
(\%)\end{array}$ \\
\hline \multicolumn{21}{|c|}{ KetoCheck powder for milk acetoacetate } \\
\hline$\geq$ trace & 41 & 99 & 2 & 94 & 1 & 3 & 68 & 97 & 6 & 84 & 1 & 9 & 88 & 91 & 12 & 69 & 1 & 18 & 95 & 80 \\
\hline$\geq$ moderate & 10 & 100 & 0 & 95 & 0 & 5 & 100 & 95 & 1 & 85 & 0 & 14 & 100 & 86 & 3 & 70 & 0 & 27 & 100 & 72 \\
\hline$\geq$ large & 2 & 100 & 0 & 95 & 0 & 5 & 100 & 95 & 0 & 85 & 0 & 15 & 100 & 85 & 0 & 70 & 0 & 30 & 100 & 70 \\
\hline \multicolumn{21}{|c|}{ Ketostix strip for urine acetoacetate } \\
\hline$\geq$ trace & 90 & 86 & 4 & 82 & 13 & 1 & 25 & 99 & 13 & 73 & 12 & 2 & 53 & 98 & 27 & 60 & 10 & 3 & 73 & 95 \\
\hline zsmall & 78 & 96 & 4 & 91 & 4 & 1 & 51 & 99 & 12 & 82 & 3 & 3 & 78 & 96 & 23 & 67 & 3 & 7 & 89 & 91 \\
\hline$\geq$ moderate & 49 & 99 & 2 & 94 & 1 & 3 & 74 & 97 & 7 & 84 & 1 & 8 & 90 & 92 & 15 & 69 & 1 & 15 & 96 & 82 \\
\hline$\geq$ large & 12 & 100 & 1 & 95 & 0 & 4 & 100 & 96 & 2 & 85 & 0 & 13 & 100 & 87 & 4 & 70 & 0 & 26 & 100 & 73 \\
\hline zvery large & 4 & 100 & 0 & 95 & 0 & 5 & 100 & 95 & 1 & 85 & 0 & 14 & 100 & 86 & 1 & 70 & 0 & 29 & 100 & 71 \\
\hline \multicolumn{21}{|c|}{ KetoTest strip for milk BHBA ( $\mu \mathrm{mol} / \mathrm{L})$} \\
\hline$\geq 50$ & 88 & 90 & 4 & 86 & 9 & 1 & 32 & 99 & 13 & 77 & 8 & 2 & 61 & 98 & 26 & 63 & 7 & 4 & 79 & 94 \\
\hline$\geq 100$ & 73 & 96 & 4 & 91 & 4 & 1 & 46 & 99 & 11 & 81 & 4 & 4 & 74 & 95 & 22 & 67 & 3 & 8 & 88 & 89 \\
\hline$\geq 200$ & 27 & 99 & 1 & 94 & 1 & 4 & 69 & 96 & 4 & 84 & 1 & 11 & 88 & 88 & 8 & 70 & 0 & 22 & 95 & 76 \\
\hline$\geq 500$ & 3 & 100 & 0 & 95 & 0 & 5 & 100 & 95 & 0 & 85 & 0 & 15 & 100 & 85 & 1 & 70 & 0 & 29 & 100 & 71 \\
\hline$\geq 1000$ & 2 & 100 & 0 & 95 & 0 & 5 & 100 & 95 & 0 & 85 & 0 & 15 & 100 & 85 & 0 & 70 & 0 & 30 & 100 & 70 \\
\hline
\end{tabular}

${ }^{1}$ KetoCheck, Great States Animal Health, St. Joseph, MO: Levels correspond to the degree of purple discoloration (none, light, intermediate and dark); Ketostix, Bayer Corporation, Elkhart, IN: Trace $=490 ;$ small $=1470 ;$ moderate $=3920 ;$ large $=7840$ and very large $=15,700 \mu$ mol/L of acetoacetate $($ AcAc $)$ KetoTest, Sanwa Kagaku Kenkyusho Co. Ltd., Nagoya, Japan.

${ }^{2} \mathrm{Se}=$ Sensitivity: proportion of diseased animals that test positive.

${ }^{3} \mathrm{Sp}=$ Specificity: proportion of nondiseased animals that test negative.

${ }^{4}+\mathrm{PV}=$ Positive predictive value: proportion of animals with a positive test that are diseased

${ }^{5}-\mathrm{PV}=$ Negative predictive value: proportion of animals with a negative test that are nondiseased. 


\section{Ketostix strip Urine acetoacetate}
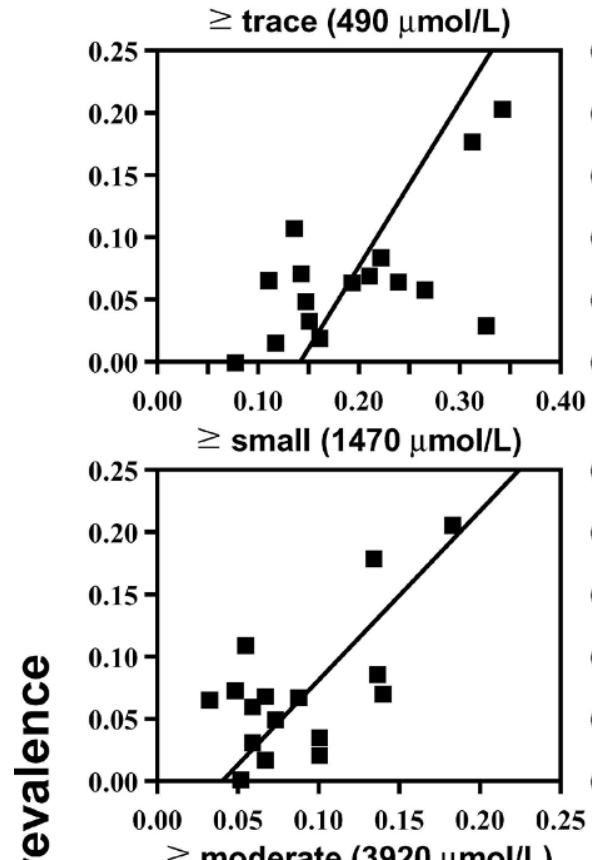

$\geq$ moderate $(3920 \mu \mathrm{mol} / \mathrm{L})$

온
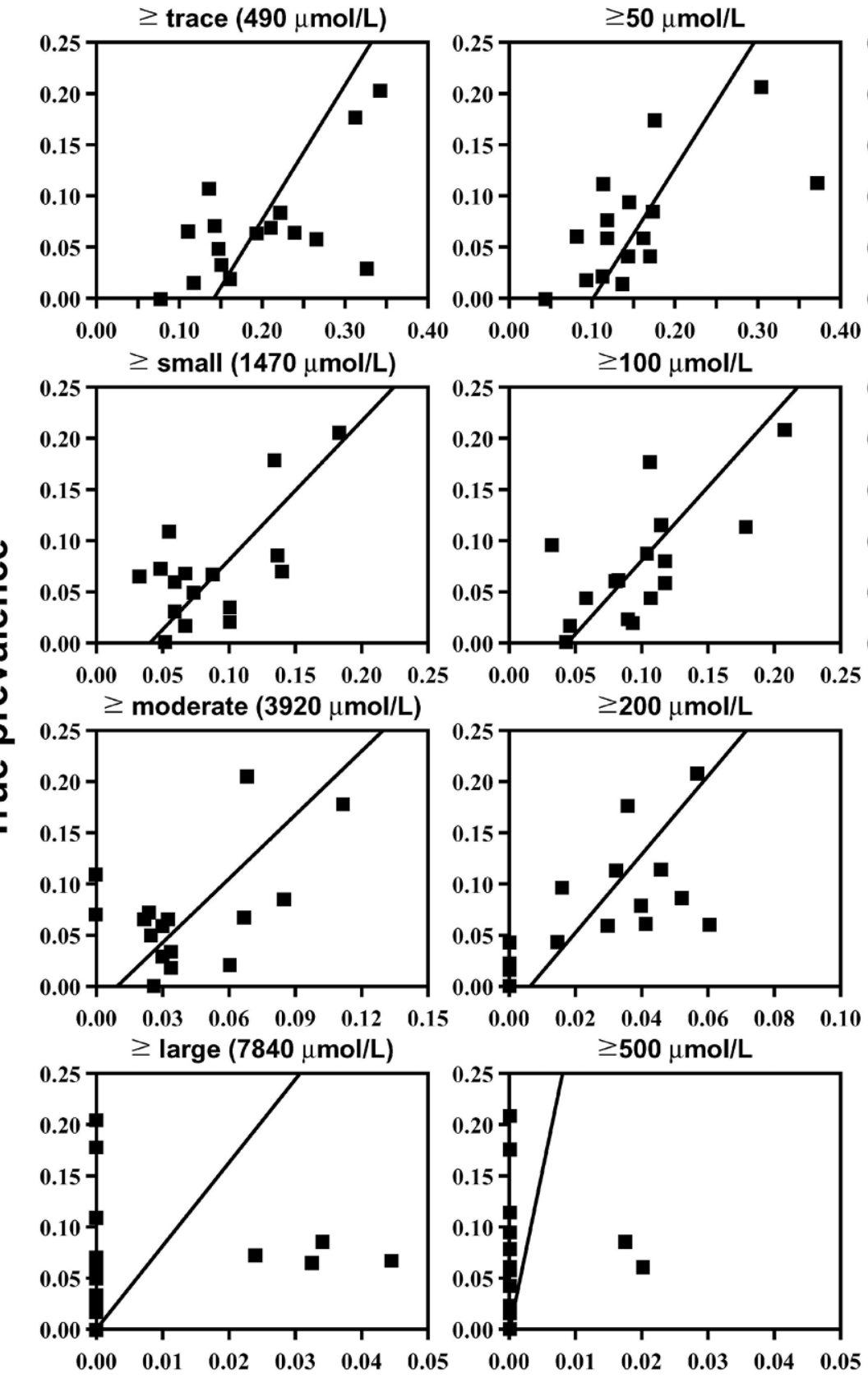

KetoTest strip

Milk BHBA
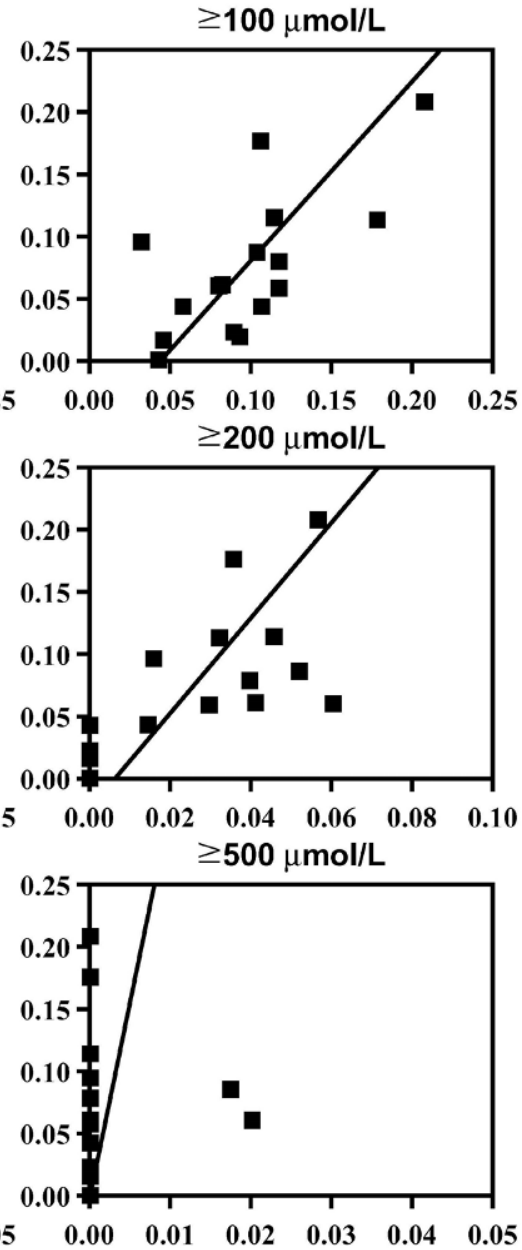

\section{Apparent prevalence}

Figure 2. Relationship between the true prevalence of subclinical ketosis (defined as BHBA concentration $\geq 1400 \mu$ mol/L of serum) on the $\mathrm{y}$-axis, and the apparent prevalence on the $\mathrm{x}$-axis ( $\mathrm{n}=16$ sampling days). The line is the predicted true prevalence estimated as a function of the apparent prevalence, overall sensitivity, and overall specificity of each test (Predicted true prevalence $=[$ Apparent prevalence + Specificity - 1] divided by [Sensitivity + Specificity - 1]). The tests are the KetoCheck (Great States Animal Health, St. Joseph, MO), the Ketostix (Bayer Corporation, Elkhart, IN), and the KetoTest (Sanwa Kagaku Kenkyusho Co. Ltd., Nagoya, Japan). The highest cut-off point for each test is not represented. Note that the scale of the $\mathrm{x}$-axis changes across plots to accommodate the variation in apparent prevalence. 
(Figure 2). The standard deviation of the difference between the predicted prevalence and the actual true prevalence was $5 \%$ at the "small" level of urine ketones and $6 \%$ at the "moderate" level. Prevalence predicted with the KetoTest strip test at the cut-off points of 100 and $200 \mu \mathrm{mol}$ of BHBA/L of milk had a similar level of precision. Except for $1 \mathrm{~d}$, the KetoCheck powder used at the trace level also had a similar precision. Adjusting for the specificity and sensitivity of the cowside tests to estimate the true prevalence allowed addressing the bias in the estimate, but it did not make the prediction precise.

Higher cut-off points were not suitable to approximate subclinical ketosis prevalence, because with such poorly sensitive but very specific tests a difference of \pm 1 test-positive cow could change the prediction of the true prevalence by a very large amount in these groups of moderate size.

The cowside tests may allow differentiation of a $5 \%$ prevalence from a prevalence of $20 \%$ and higher, but over-interpretation of small variations in apparent prevalence is not recommended. Differentiation over a wider range of prevalence could not be evaluated in this study. However, in situations where false-positive and false-negative herd diagnostics are much more costly than individual diagnostic errors, confirmation of the cowside tests by additional testing (e.g., serum BHBA analysis of an adequate number of animals) may be warranted for better estimation of the herd prevalence.

The study population in this study may have included some cows actually suffering from clinical ketosis usually caused by higher concentrations of ketone bodies. However, such distinction between clinical and subclinical ketosis is usually not made in subclinical ketosis studies (Andersson, 1988; Duffield, 2000), as clinical status may not be known at the time of the study. Also, the clinical status of TMR-fed cows housed in freestalls may be difficult to assess or clinical signs may be confounded with those of other concurrent diseases. Therefore, it is actually the ability of the tests to detect levels of ketone bodies at least subclinically elevated that was evaluated in this study within a population containing mostly visibly normal fresh cows. However, this need not be viewed as a problem as the evaluation of a test's performance should be done in a population similar to the one where the tests are intended to be used (Ransohoff and Feinstein, 1978; Martin, 1988; Dohoo et al., 2003). One would not necessarily know the clinical status of the animals before screening for subclinical ketosis and would therefore include these animals in the screening process.
Accordingly, the results of this study may not be applicable to the clinical setting of sick-cow examinations. The prevalence of ketosis is likely to be higher in sick cows than in than in normal fresh cows, changing the number of each diagnostic error and the predictive values of the tests. Also, the different characteristics of the group of sick animals (like the distribution of BHBA concentration) may also alter the sensitivity and the specificity of the tests (Ransohoff and Feinstein, 1978; Martin, 1988).

\section{CONCLUSIONS}

The KetoTest and the Ketostix tests are useful tools for diagnostic of individual cases of subclinical ketosis and, on a herd basis, may indicate the necessity for further investigation of the situation. To evaluate the cost-effectiveness of subclinical ketosis screening, further research is needed to describe the extent to which the monetary losses associated with subclinical ketosis can be recuperated by early diagnosis and treatment and the effect of the sampling frame on the net sensitivity and specificity of the monitoring program.

\section{ACKNOWLEDGMENTS}

The authors gratefully acknowledge Balchem Corporation and Elanco Animal Health for providing financial support for testing. The authors also thank Jodi Olson, Jim Lewis, and Dan Preisler for their valuable assistance in the sample collection and testing procedures.

\section{REFERENCES}

Adler, J. H., S. J. Robert, and R. G. D. Steel. 1956. The relation between reactions to the Ross test on milk and urine and the degree of ketonemia in dairy cows. Cornell Vet. 47:101-111.

American Medical Association. 2004. Instructions for authors. JAMA. 291:125-129. Article options: Système International (SI) Conversion Table. Online. Available: http://jama.ama-assn.org/ cgi/content/full/291/1/125/DC6.

Andersson, L. 1984. Concentrations of blood and milk ketone bodies, blood isopropanol and plasma glucose in dairy cows in relation to the degree of hyperketonaemia and clinical signs. Zentralbl. Veterinaermed. Reihe A 31:683-693.

Andersson, L. 1988. Subclinical ketosis in dairy cows. Metabolic diseases of ruminant livestock. Vet. Clin. North Am. Food Anim. Pract. 4:233-251.

Andersson, L., and U. Emanuelson. 1985. An epidemiological study of hyperketonaemia in Swedish dairy cows; determinants and the relation to fertility. Prev. Vet. Med. 3:449-462.

Dawson, B., and R. G. Trapp. 2001. Basic \& Clinical Biostatistics. 3rd ed. McGraw-Hill Book Co., New York, NY.

Dohoo, I. R., and S. W. Martin. 1984. Subclinical ketosis: prevalence and associations with production and disease. Can. J. Comp. Med. 48:1-5

Dohoo, I. R., S. W. Martin, and H. Stryhn. 2003. Screening and diagnostic tests. Pages 85-120 in Veterinary Epidemiologic Research. AVC Inc., Charlottetown, Canada. 
Duffield, T. F. 1997. Effects of a monensin controlled release capsule on energy metabolism, health, and production in lactating dairy cattle. D.V.Sc. Thesis, Univ. Guelph, Canada.

Duffield, T. F. 2000. Subclinical ketosis in lactating dairy cattle: Metabolic disorders of ruminants. Vet. Clin. North Am. Food Anim. Pract. 16:231-253.

Duffield, T. F., D. F. Kelton, K. E. Leslie, K. D. Lissemore, and J. H. Lumsden. 1997. Use of test day milk fat and milk protein to detect subclinical ketosis in dairy cattle in Ontario. Can. Vet. J. 38:713-718.

Duffield, T. F., D. Sandals, K. E. Leslie, K. Lissemore, B. W. McBride, J. H. Lumsden, P. Dick, and R. Bagg. 1998. Efficacy of monensin for the prevention of subclinical ketosis in lactating dairy cows. J. Dairy Sci. 81:2866-2873.

Enjalbert, F., M. C. Nicot, C. Bayourthe, and R. Moncoulon. 2001. Ketone bodies in milk and blood of dairy cows: Relationship between concentrations and utilization for detection of subclinical ketosis. J. Dairy Sci. 84:583-589.

Geishauser, T., K. Leslie, D. Kelton, and T. F. Duffield. 1998. Evaluation of five cowside tests for use with milk to detect subclinical ketosis in dairy cows. J. Dairy Sci. 81:438-443.

Geishauser, T., K. Leslie, D. Kelton, and T. F. Duffield. 2001. Monitoring for subclinical ketosis in dairy herds. Compend. Contin. Educ. Prac. Vet. 23:S65-S71.

Geishauser, T., K. Leslie, J. Tenhag, and A. Bashiri. 2000. Evaluation of eight cowside ketone tests in milk for detection of subclinical ketosis in dairy cows. J. Dairy Sci. 83:296-299.
Herdt, T. H. 2000. Variability characteristics and test selection in herd-level nutritional and metabolic profile testing: Metabolic disorders of ruminants. Vet. Clin. North Am. Food Anim. Pract. 16:387-403.

Jorritsma, R., S. J. C. Baldee, Y. H. Schukken, T. Wensing, and G. H. Wentink. 1998. Evaluation of a milk test for detection of subclinical ketosis. Vet. Q. 20:108-110.

Kauppinen, K. 1983. Prevalence of bovine ketosis in relation to number and stage of lactation. Acta Vet. Scand. 24:349-361.

Martin, S. W. 1984. Estimating disease prevalence and the interpretation of screening test results. Prev. Vet. Med. 2:463-472.

Martin, S. W. 1988. The interpretation of laboratory results: Investigation of disease outbreaks and impaired productivity. Vet. Clin. North Am. Food Anim. Pract. 4:61-78.

Nielen, M., M. G. A. Aarts, A. G. M. Jonkers, T. Wensing, and Y. H. Schukken. 1994. Evaluation of two cowside tests for the detection of subclinical ketosis in dairy cows. Can. Vet. J. $35: 229-232$

Osborne, T. M., K. E. Leslie, T. Duffield, C. S. Petersson, J. Ten Hag, and Y. Okada. 2002. Evaluation of Keto-Test in urine and milk for the detection of subclinical ketosis in periparturient Holstein dairy cattle. Pages 188-189 in Proc. 35th Annu. Conv. Am. Assoc. Bov. Pract., Madison, WI. Am. Assoc. Bov. Pract., Stillwater, OK.

Ransohoff, D. F., and A. R. Feinstein. 1978. Problems of spectrum and bias in evaluating the efficacy of diagnostic tests. New England J. Med. 299:926-930.

Schultz, L. H. 1971. Management and nutritional aspects of ketosis. J. Dairy Sci. 54:962-973. 